\title{
Impact of Parental Migration on Health of Left Behind Children
}

\author{
Sushil Sharma ${ }^{1}$, Bhimsen Devkota ${ }^{2} \&$ Devaraj Acharya ${ }^{3}$ \\ ${ }^{1} \mathrm{PhD}$ Scholar, Graduate School of Education, Tribhuvan University, Kathmandu, Nepal \\ ${ }^{2}$ Professor, Mahendra Ratna Campus, Tribhuvan University, Kathmandu, Nepal \\ ${ }^{3}$ Bhairahawa Multiple Campus, Tribhuvan University, Rupandehi, Nepal \\ Correspondence: Sushil Sharma, Graduate School of Education, Faculty of Education, Tribhuvan University, \\ Kirtipur, Kathmandu, Nepal. Tel: 977-9856032273
}

Received: October 14, 2020 Accepted: December 23, 2020 Online Published: January 3, 2021

doi:10.5539/gjhs.v13n2p77 URL: https://doi.org/10.5539/gjhs.v13n2p77

\begin{abstract}
After the adoption of liberal economic policy, Nepal entered into the international work force market. Human resource moves abroad seeking for employment opportunities. The globalization of workforce on one hand benefit to the country with a huge amount of inward remittance and on the other brings different bi-products in the country. The physical and emotional effects on the left-behind children [LBC] have come on the forefront as a burning issue. Absence of parents in the family has resulted in children's sedentary and complicated life as well.

However, health-related problems such as cough or respiratory difficulties and diarrhoea have been a major concern among the LBC. The absence of guardians results in nutritional problems such as height / weight for the age. Out of the parents, mother's migration results in severe consequences. It does not only have an effect on children's basic immunization and breastfeeding, but also effects on personal hygiene and sanitation. However, affordability of better diet, fancy outfits and health care facilities has been available to LBC with their growing access to remittance.
\end{abstract}

Keywords: left-behind children, nutritional status, mental health, parental migration, remittance

\section{Introduction}

With the dawn of globalization, the numbers of migrant people have been growing throughout the world. The majority of the migrants comprises of labour migrants living in a low and middle-economic status and the job seekers (International Organization for Migration [IOM], 2019). Employment opportunity has been one of the key motivating factors of migration. As a result, the children become left behind and have to survive under the care of other family members. Ratha, De, Schuettler, Seshan, \& Yameogo (2018) indicate international migrants send near and about US\$613 billion annually as remittances to their countries of origin.

Regarding to Nepalese history on international labour migration [ILM], it can be traced back to the Sugauli treaty of 1816 (Ferrie \& Hatton, 2015). Since then Britain started to recruit Nepali Gurkhas as mercenaries for East India Company (Ferrie \& Hatton, 2015). As a mercenary, some one hundred thousands of Nepalese Gurkhas served the British Kingdom during both the world wars (IOM, 2019). Since the mid-1980s, Nepalese started to migrate to the Gulf states and Malaysia for work (International Labour Organization [ILO], 2018).

Nepal's entry to the world of economic liberalization in the decade of 1990s has opened avenue in the realm of international employment opportunities (IOM, 2019). It created new job opportunities all over the world. After the adoption of this policy, the domestic economy of the country has got life with the growing remittances. However, after the assimilation to this new economic system, certain bi-products have gradually come to light (Ministry of Labour and Employment, 2018). The psycho-social effects and disintegration in families have come forefront as major challenges (International Organization for Migration [IOM] \& Save the Children, 2018). Following the people's movement of 1990 (JanaandolanI[people's movement]) the liberal policy of ILM was institutionalized (MoLE, 2018). Then after, Nepal explored more areas of foreign and cross-border employment to impart more remittance and revenue as well as foreign currency (MoLE, 2018).

With the gradual growth in numbers of international migrants, it left many homes without the guardians (IOM, 2019). That is to say, the growing number of international migrants reciprocally saw the growing number of LBC. Besides, the absence of parents in the family, the trend of international migration approached with the bunch of 
remittance in the families allowing more investments in the wellbeing of children (Davis \& Brazil, 2016).

\section{Methods for Identification of Reviews}

We have attempted to consult the related literature and resources available either in printed or in internet form. Here, the search method is pre-planned to identify all available thesis, books and peer-review journals etc. The terms; 'left behind children' and 'health' are surfed to find the online discourse. Narrative overview of the literature synthesizing the findings of literature from the computerized databases, hand searches, and authoritative texts are also used.

The searches of the online databases are conducted for the literature review. PubMed, Hinari, Research gate, Google scholar etc. are used as the internet resources. Besides these, narrative reviews, books, and article from bibliographic references have been reviewed for broader perspective.

As a part of $\mathrm{PhD}$ desertions, in choosing the literature, the texts before 2010 are excluded in this paper. The texts related to internal migration are also excluded. Likewise, the reviews concerning to migrants who have been abroad more than six months are included in this paper. In reviewing literature, the texts related to physical and mental wellbeing, personal hygiene, nutritional conditions, etc. are included.

\section{Discussion and Findings}

Health is one of the society's most important values and has been prioritized as one of the sustainable development goals (United Nations [UN], (2016). It is also the most precious values in life since it is related to the overall health of a society and nation (Islam, Khan, \& Mondal, 2019). Tang, Choi, Deng, Bian, and Hu (2019) believe health as the symbol of a happy and satiated life. Good health relies on income, diet habit, lifestyles and emotional aspects (Gao et al., 2010). One who has better income can invest in better diet and nutritious food to maintain good health (Gao et al., 2010; Islam et al., 2019).

The aims of this study are to map and converse about the available literature on the role of remittances on health of LBC. This literature supports to add by undertaking the matter on how the literature view the effect of remittances on better diet, fancy outfits and health care facilities. Giving the impression, of being at interactions between remittances on the one hand, and health on the other, this review reflects on the following questions: what is the significance of migration and remittances for the developing countries? How parental international migration [PIM] effect on LBC's health?

Though abroad migration is counted to be beneficial for the remittance, it has created certain bi-products (IOM, 2019). When one of the parents departs abroad for migration, the rest of the family members suffer back in home. That is to say, they have to undergo some psychological and emotional distresses like sadness, insomnia, obsessive thinking, loneliness, and crying (Adhikari, 2019; Dahal, 2016; Gao et al., 2010; Tang et al., 2019). Approximately 43 percent of the children age 12-17 years are found to have psychological distresses due to parental migration in Thailand (Jampaklay et al., 2018). LBC experiences anxiety and poor living conditions compared to Non- left behind children [NLBC] in China (Song, Chen, \& Zhang, 2018;Wang et al., 2019).

According to Man, Mengmeng, Lezhi, Ting, and Jingping (2017) psychosocial problems are found prevalent among the adolescents older than 14 years in China. However, Adhikari (2019) and Viet Nguyen (2016) argue that girls have negative consequences in their health than that of boys after mother's migration. With the absence of a mother in the family, girls have to encounter several health problems because they miss somebody to share their problem (Adhikari, 2012). PIM has negative impacts on the wellbeing and psychological accompaniment of LBC (Adhikari et al., 2014). Especially, migration of mother in the family has an adverse effect on their security, households' environment, psychological aspects, education, health etc. in Nepalese context (Adhikari, 2019). Since girls can openly express their health problems with their mothers, they feel alone at home even if their father are with them (Adhikari, 2019; Tong, Yan, \& Kawachi, 2019).

Loneliness, grievances, low self-esteem and fears are the emotional experiences that the LBC encounter where loneliness is the most common (Zhao, Egger, Stein, \& McGregor, 2020). The mental health of LBC is found to be better than NLBC (Lin, 2016). Adhikari et al. (2014) indicate the mother's migration has an association with mental health problems of the LBC in Thailand. PIM often disrupts parent-child relationships and effects on physical health and psychological wellbeing of LBC (Zhao, Sun, Guo, \& Liu, 2018).

Migration of mothers results in psycho-social disruptions in for children. Multivariate regression analyses show that PIM corresponds to worse emotional symptoms (Adhikari, 2012). However, a different result has been seen in Moldova and Georgia in case of father, mother or both PIM suggesting different impacts in male and female children (Vanore, 2015). 
International Organization for Migration \& Save the Children (2018) state that children whose fathers are absent from the family tended of having an experience of physical as well as mental abuse in Bangladesh. Parental absenteeism in the family seems to affect the psychological development and sense of insecurity in children. They feel less confident, insecure, loneliness and carelessness (Iqbal, Mozmi, Iqbal, \& Saeed, 2014). Similarly, the male LBC is more vulnerable to psychopathology in SriLanka (Wickramage et al., 2015). LBC are more prone to psychological and emotional stress, sense of abandonment, and low-self-esteem (Garza, 2010).

IOM \& Save the Children (2018) conducted a comparative study in Bangladesh which suggests children of domestic migrants have fewer probabilities of major health issues than children of international migrants. Loneliness has been the most common experience of LBC ( $\mathrm{Su}, \mathrm{Li}$, Lin, Xu, \& Zhu, 2013).

LBC whose both parents are absent in family has worst physical health, higher risk of injury, behavioural problems and lower nutrition (Fu, Bo, Xue, \& Yuan, 2017). The LBC who are under the care of young caregivers are found to indulge in alcoholism, smoking, internet addiction and the emotional problems (Adhikari et al., 2014; Fu et al., 2017; Yeoh \& Lam, 2016).

PIM is associated with a higher frequency of mental health difficulties, including emotional and behavioural problems as well as hyperactivity (Song et al., 2018). The suicidal temptation is higher in children whose both parents are absent in family than the children who live with both or at least one of the parents (Chang et al., 2017; Shen et al., 2015). The highest risk is noted in boys aged between 6 and 11 years. They are found to be affected by somatic complaints, schizophrenia and depression (Iqbal et al., 2014; Qu et al., 2018). Children living with father rather than mother demonstrates such tendencies in Bangladesh (Islam et al., 2019).

Concerning the nutritional status mixed results have been noticed in different countries and contexts. The nutrition status in the LBC age less than 5 years whose mother has migrated is lower than those children who are under maternal care (Hysing, Petrie, Bøe, \& Sivertsen, 2017). Likewise, 34 percent of LBC are underweighted in Sri Lanka compared to that of NLBC which comes to be 18 percent (Wickramage et al., 2015). Similarly, 30 percent of the LBC are found underweighted compared to the children in non-migrant households in Thailand that accounted for 18 percent (Jampaklay \& Richter, 2018). It shows there are an association between the child growth and nutrition (weight-height and BMI).

PIM has also a positive impact on the dietary habit of LBC. In Bangladesh, LBC of the migrant parent(s) are better off in terms of nutritional development than the children living with parents (Islam et al., 2019). Similarly, younger children (aged 6 to 12) are more likely to be overweight than older ones (aged 12 or older) (Brauw \& Mu, 2011). On the basis of indicators prepared to measure the progress of child growth and nutrition across different age groups, we found that NLBC of age group 3-5 years have a significant lower proportion of weight/height for-age scores relative to LBC (Zhou et al., 2015). Younger children of age 6 to 12 years are found to be over weighted in China (Zhou et al., 2015). The prevalence of wasting, overweight and obesity is found in LBC in comparison to NLBC (Adhikari, 2012; Mo et al., 2014).

IOM \& Save the Children (2018) reported that the LBC are less healthy in terms of height and weight in comparison to children of non-migrants. Mother migration has been found responsible for children's height/ weight-for-age (Mo et al., 2016). However, different result has been observed in Bangladesh that the children of internal migrants are found healthier (i.e. taller with higher weight) compared to the children of international migrants.

PIM makes difference to the upbringings of children in Ghana, Angola and Nigeria. In these countries, poor well-being of children is seen with mother's migration and fathers assigning role as caregivers. It shows the result of a survey in three African countries during 2010-11 (Ghana N=2760; Angola N=2243; Nigeria N=2168) in which pupils of secondary schools are forced to live with caregivers (Mazzucato et al., 2015). Shen et al. (2015) put forth a different idea that LBC usually have better living conditions than the children living with parents.

LBC tends to have more conflict with classmates and higher chance of clash and argument (Luo et al., 2019). They are found to be at higher risk of sedentary life, internet addiction, use of tobacco and narcotics. Especially, girls are more likely to consume an excessive sweet beverage, watch more TV and drink alcohol and self-efficacy (Adhikari et al., 2014; Fu et al., 2017; Gao et al., 2010; Yeoh \& Lam, 2016). However, Acharya, Ghimire, Bhandari, Ghimire, and Jones (2019) projected towards the possibility of higher consumption of meat and eggs with increased purchasing capacity. Islam et al. (2019) also found that PIM enhances the affordability of better diet, garments, health care facilities and better sanitation in Bangladesh.

Prevalence of diseases such as cough or respiratory difficulties and diarrhoea as well as an emotional disorder noticed higher in LBC (Tang et al., 2019). But, the rate of helminths infection has been found higher among the 
children living with both parents (39\%) than LBC (25\%) and anaemia is seen almost equal in both group (Zhou et al., 2015). A study conducted among 558 school children found that there is no relationship between PIM and children's sickness in Thailand (Nanthamongkolchai, Munsawaengsub, \& Nanthamongkolchai, 2011).

Most of the children in migrant households are likely to get sick compared to non-migrant families (Botezat \& Pfeiffer, 2014). So, it is important to understand that the presence of mother together with children makes a difference in child health (Viet Nguyen, 2016). Adolescents whose mothers migrate elsewhere have low self-efficacy and are at elevated risk of smoking and alcoholism (Gao et al., 2010). Gibson, Mckenzie, and Stillman (2011) reported that migration is associated with the lower health indication of least breastfeeding and inadequate vaccinations.

Inadequate care at home usually results in poor health conditions in the children (Zhao et al., 2018). Poor health condition has higher probability of school failure, grade retention and dropout (Benjamin, 2016). He also suggests grandparents' care may be inadequate to meet the needs of children. Health services provided at school can alleviate the problem of absenteeism, and late-coming tendency in children (Benjamin, 2016).

PIM has a long-lasting impact on the behaviour of children (Zhang, 2019). Poor communication between parent and children is associated with children's disturbed mental health (Iqbal et al., 2014). Problems in communication with mother or father is associated with emotional symptoms and hyperactivity ( $\mathrm{Su}$ et al., 2013).

$\mathrm{Su}$ et al. (2013) explain that communication plays a significant role to cope with the emotional and behavioural problems. Children, who are in harmonious communication with parents tends to be more happier (Corballis, 2015; Runcan, Constantineanu, Ielics, \& Popa, 2012). If parents and teachers maintain effective relationships with children, it sets the foundation for the emotional wellbeing of the children (Benjamin, 2016).

The existing literature, suggests that the effect of PIM in all cases and condition do not have an adverse impact, however; it is determined by the person who has migrated. That is to mean, in some countries mother's migration has a negative impact whereas less impact on father's migration. Similarly, some literature suggests the health of children improved with increased affording capacity while others suggest poorer performance in comparison to NLBC.

This study explores and analyses the current situation of LBC in regard to their health status. The reviewed articles suggest that both parent's migration has negative impacts to their children. It is found that in most of the cases both parents migration has effect on overall health issues. Among the parents mother's migration has been found to have more negative impacts. Migration can be used for the benefit of children if father is as migrants. However, if both parents are on migration the children should be left with responsible caregivers whom the children feel love, care and attachment.

Besides, this study gives input to formulate and implement the plans, programs and policies. The society, school and parents may realize their role towards the importance of quality of life and supportive environment to enhance child's health. It will unravel the correlation between PIM and health so that the family and society can make their perceptions towards international migration. It helps to diagnose the issues of LBC more accurately and objectively to mitigate the negative consequences and create a child-friendly environment.

\section{Conclusion}

PIM has financial benefits, however; it has created certain bi-products. With the income of remittance, children have better access to health facilities and sanitation but they are deprived of parental care and nurture. Parental presence is necessary to prevent from Insomnia, loneliness, suicidal ideation, and depression. Moreover, Health literacy is a basic prerequisite for better health. In creating health awareness in a family, mothers have more important roles than fathers. Mother's migration has to pay a higher cost than father's migration in the family in regard to children's health and well beings. For better health of children mother's presence is the most essential, especially, to the children who require breastfeeding and vaccinations. Higher risk of injury, behavioural problems and lower nutrition are the cause of PIM in LBC. Children under the care of caregivers indulge in alcoholism, smoking and internet addiction. Higher risk of sedentary life, internet addiction, use of tobacco and narcotics in boys are associated with parental migration and girls are more likely to consume an excessive sweet beverage, alcoholism and engage more on television. However; frequent communication and counseling from the parents can minimize the effect. Despite having some negative consequences to the LBC, PIM can be beneficial if parents fulfill their sincere responsibilities and are connected psychologically to the children.

\section{Competing Interests Statement}

The authors declare that there are no competing or potential conflicts of interest. 


\section{References}

Acharya, Y., Ghimire, D. J., Bhandari, P., Ghimire, R., \& Jones, A. D. (2019). Household migration and children ' s diet in Nepal : an exploratory study. BMC Research Notes, 1-6. https://doi.org/10.1186/s13104-019-4430-x

Adhikari, B. (2019). The consequences of mother international migration to the left behind girls for their education, health and psychosocial development in Chitwan district, Nepal. Journal of Management, Technology \& Social Sciences, (March). https://doi.org/10.13140/RG.2.2.36464.51205

Adhikari, R. (2012). The impact of parental migration on the health of children living separately from parents. The degree of Doctoral Philosophy, Faculty of Graduate Studies, Mahidol University. Retrieved from http://103.69.125.248:8080/jspui/bitstream/123456789/70/1/All thesis_combined.pdf

Adhikari, R., Jampaklay, A., Chamratrithirong, A., Richter, K., Pattaravanich, U., \&Vapattanawong, P. (2014). The impact of parental migration on the mental health of children left behind. Journal of Immigrant and Minority Health, 16(5), 781-789. https://doi.org/10.1007/s10903-013-9809-5

Benjamin, M. (2016). Teacher and parent influence on childhood learning outcomes.Dissertation Abstracts International Section A: Humanities and Social Sciences. Walden University. Retrieved from https://scholarworks.waldenu.edu/cgi/viewcontent.cgi?article=2777\&context=dissertations

Botezat, A., \& Pfeiffer, F. (2014). The impact of parents migration on the well-being of children left behind initial evidence from Romania. ZEW-Centre for European Economic Research Discussion Paper, (14-029). https://doi.org/10.2139/ssrn.2432946

Brauw, A., \& Mu, R. (2011). Migration and the Overweight and Underweight Status of Children in Rural China. Food Policy, 36, 88-100. https://doi.org/10.1016/j.foodpol.2010.08.001

Chang, H., Yan, Q., Tang, L., Huang, J., Ma, Y., Ye, X., \& Yu, Y. (2017). A comparative analysis of suicide attempts in left-behind children and non-left-behind children in rural China. PLoS ONE, 12(6), 1-15. https://doi.org/10.1371/journal.pone. 0178743

Corballis, M. C. (2015). Theory of mind. The Recursive Mind, 129-130. https://oi.org/10.1515/9781400851492-012

Dahal, G. (2016). Urgency of migrant health policy in Nepal. MOJ Public Health, 4(6), 172-173. https://doi.org/10.15406/mojph.2016.04.00098

Davis, J., \& Brazil, N. (2016). Migration, remittances and nutrition outcomes of left-behind children: A national-level quantitative assessment of Guatemala. PLoS ONE, 11(3), 1-17. https://doi.org/10.1371/journal.pone.0152089

Ferrie, J. P., \& Hatton, T. J. (2015). Two centuries of international migration. Handbook of the Economics of International Migration (Vol. 1). https://doi.org/10.1016/B978-0-444-53764-5.00002-5

Fu, M., Bo, W. V., Xue, Y., \& Yuan, T. F. (2017). Parental absence accompanies worse academic achievements: Evidence based upon a sample of left-behind children in rural China. Frontiers in Education, 2(August), 1-7. https://doi.org/10.3389/feduc.2017.00038

Gao, Y., Li, L. P., Kim, J. H., Congdon, N., Lau, J., \& Griffiths, S. (2010). The impact of parental migration on health status and health behaviours among left behind adolescent school children in China. BMC Public Health, 10(56), 1-10. https://doi.org/10.1186/1471-2458-10-56

Garza, R. D. La. (2010). Migration, development and children left behind: A multidimensional perspective. Social and Economic Policy Working Paper. New York. Retrieved from http://www2.unicef.org/socialpolicy/files/Postscript_Formatted_Migration_Development_and_Children_L eft_Behind.pdf

Gibson, J., Mckenzie, D., \& Stillman, S. (2011). Remaining household members : Omnibus results. The Review of Economics and Statistics, 93(4), 1297-1318.

Hysing, M., Petrie, K. J., Bøe, T., \& Sivertsen, B. (2017). Parental work absenteeism is associated with increased symptom complaints and school absence in adolescent children. BMC Public Health, 17(1), 1-7. https://doi.org/10.1186/s12889-017-4368-7

International Labour Organization (ILO). (2018). International Labour Migration Statistics in South Asia. Retrieved from https://www.ilo.org/newdelhi/whatwedo/publications/WCMS_645286/lang--en/index.htm

International Organization for Migration [IOM]. (2019). Migration in Nepal: A country profile 2019. Retrieved 
from https://publications.iom.int/system/files/pdf/mp_nepal_2019.pdf

International Organization for Migration \& Save the Children. (2018). Social cost of migration on children left behind due to labour migration. International Organization for Migration (IOM) \& Save the Children. Retrieved from https://bangladesh.iom.int/sites/default/files/publication/Social-Cost-of-Migration-Book.pdf

Iqbal, S., Mozmi, R. A., Iqbal, F., \& Saeed, M. (2014). International Male Migration and Its Impact on Education of Children and Wives Left Behind: Evidence from Punjab Pakistan. Open Journal of Social Sciences, 02(06), 464-467. https://doi.org/10.4236/jss.2014.26054

Islam, M. M., Khan, M. N., \& Mondal, M. N. I. (2019). Does parental migration have any impact on nutritional disorders among left-behind children in Bangladesh? Public Health Nutrition, 22(1), 95-103. https://doi.org/10.1017/S1368980018002963

Jampaklay, A., \& Richter, K. (2018).The impact of parental absence on early childhood development in the context of Thailand. https://doi.org/10.1177/0117196818767439

Jampaklay, A., Richter, K., Tangchonlatip, K., \& Nanthamongkolchai, S. (2018). The impact of parental absence on early childhood development in the context of Thailand. Asian and Pacific Migration Journal, 27(2), 209-230. https://doi.org/10.1177/0117196818767439

Lin, L. (2016). Problems and Countermeasures of rural left behind children in the context of urbanization in China, (Sshme), 123-132. https://doi.org/10.2991/sshme-16.2016.24

Luo, J., Zou, J., Ji, M., Yuan, T., Sun, M., \& Lin, Q. (2019). Emotional and behavioral problems among 3-to 5 -year-olds left-behind children in poor rural areas of Hunan province: a cross-sectional study. International Journal of Environmental Research and Public Health, 16(21), 1-12. https://doi.org/10.3390/ijerph16214188

Man, Y., Mengmeng, L., Lezhi, L., Ting, M., \& Jingping, Z. (2017). The psychological problems and related influential factors of left-behind adolescents (LBA) in Hunan, China: A cross sectional study. International Journal for Equity in Health, 16(1), 1-12. https://doi.org/10.1186/s12939-017-0639-2

Mazzucato, V., Cebotari, V., Veale, A., White, A., Grassi, M., \& Vivet, J. (2015).International parental migration and the psychological well-being of children in Ghana, Nigeria, and Angola. Social Science and Medicine, 132, 215-224. https://doi.org/10.1016/j.socscimed.2014.10.058

Ministry of Labour and Employment. (2018). Labour Migration for Employment|A Status Report for Nepal:2015/2016-2016/2017. Government of Nepal. Kathmandu: MoLE, Government of Nepal. Retrieved from http://nepal.iom.int/jupgrade/images/stories/CoM/LabourMigration_for_Employment-A_ StatusReport_for_Nepal_201516201617_Eng.PDF

Mo, X., Xu, L., Luo, H., Wang, X., Zhang, F., \& GaiTobe, R. (2016). Do different parenting patterns impact the health and physical growth of "left-behind" preschool-aged children? A cross-sectional study in rural China. European Journal of Public Health, 26(1), 18-23. https://doi.org/10.1093/eurpub/ckv181

Nanthamongkolchai, S., Munsawaengsub, C., \& Nanthamongkolchai, C. (2011). Comparison of the health status of children aged between 6 and 12 years reared by grandparents and parents. Asia-Pacific Journal of Public Health, 23(5), 766-773. https://doi.org/10.1177/1010539511424535

Qu, G. B., Wu, W., Wang, L. L., Tang, X., Sun, Y. H., Li, J., \& Wang, J. (2018). Systematic review and meta-analysis found higher levels of behavioural problems in male left-behind children aged 6-11 years. ActaPaediatrica, International Journal of Paediatrics, 107(8), 1327-1334. https://doi.org/10.1111/apa.14199

Ratha, D. K., De, S., Schuettler, K., Seshan, G. K., \& Yameogo, N. D. (2018). Migration and remittances: recent developments and outlook-transit migration. Washington, D.C.

Runcan, P. L., Constantineanu, C., Ielics, B., \& Popa, D. (2012).The role of communication in the parent-child interaction. Procedia-Social and Behavioral Sciences, 46, 904-908. https://doi.org/10.1016/j.sbspro.2012.05.221

Shen, M., Gao, J., Liang, Z., Wang, Y., Du, Y., \& Stallones, L. (2015). Parental migration patterns and risk of depression and anxiety disorder among rural children aged 10-18 years in China: A cross-sectional study. BMJ Open, 5(12), 1-8. https://doi.org/10.1136/bmjopen-2015-007802

Song, S., Chen, C., \& Zhang, A. (2018). Effects of Parental Migration on Life Satisfaction and Academic Achievement of Left-Behind Children in Rural China-A Case Study in Hubei Province. Children, 5(7), 87. https://doi.org/10.3390/children5070087 
Su, S., Li, X., Lin, D., Xu, X., \& Zhu, M. (2013). Psychological adjustment among left-behind children in rural China: The role of parental migration and parent-child communication. Child: Care, Health and Development, 39(2), 162-170. https://doi.org/10.1111/j.1365-2214.2012.01400.x

Tang, D., Choi, W. I., Deng, L., Bian, Y., \& Hu, H. (2019). Health status of children left behind in rural areas of Sichuan Province of China: A cross-sectional study. BMC International Health and Human Rights, 19(1), 1-11. https://doi.org/10.1186/s12914-019-0191-9

Tong, L., Yan, Q., \& Kawachi, I. (2019). The factors associated with being left-behind children in China: Multilevel analysis with nationally representative data. PLoS ONE, 14(11), 1-18. https://doi.org/10.1371/journal.pone.0224205

United Nations (UN). (2016). The sustainable development goals report. New York. Retrieved from http://afghandata.org:8080/xmlui/bitstream/handle/20.500. 12138/20344/azu_acku_pamphlet_k3240_s878_2016_w.pdf

Vanore, M. (2015). Family-Member Migration and the Psychosocial Health Outcomes of Children in Moldova and Georgia. Dissertation to obtain the degree of Doctor at Maastricht University,

Viet Nguyen, C. (2016). Does parental migration really benefit left-behind children? comparative evidence from ethiopia, india, peru and vietnam. Social Science \& Medicine. https://oi.org/153, 230-239. doi:10.1016/j.socscimed.2016.02.021

Wang, F., Lin, L., Xu, M., Li, L., Lu, J., \& Zhou, X. (2019). Mental health among left-behind children in rural China in relation to parent-child communication. International Journal of Environmental Research and Public Health, 16(10). https://doi.org/10.3390/ijerph16101855

Wickramage, K., Siriwardhana, C., Vidanapathirana, P., Weerawarna, S., Jayasekara, B., Pannala, G., ... Sumathipala, A. (2015). Risk of mental health and nutritional problems for left-behind children of international labor migrants. BMC Psychiatry, 15(1). https://doi.org/10.1186/s12888-015-0412-2

Zhang, Q. (2019). China'S education disparity: Rural left-behind children and migrating children. Georgetown University, Washington, DC. https://doi.org/.1037//0033-2909.I26.1.78

Zhao, C., Egger, H. L., Stein, C. R., \& McGregor, K. A. (2020). Separation and reunification: Mental health of Chinese children affected by parental migration. Pediatrics, 142(3). https://doi.org/10.1542/peds.2018-0313

Zhao, Q., Sun, X., Guo, P., \& Liu, X. (2018). China's Migrant and Left-behind Children: Correlation of Parental Migration on Health, Cognitive and Non-cognitive Outcomes. 30th International Conference of Agricultural Economists. https://doi.org/10.22004/AG.ECON.277164

Zhou, C., Sylvia, S., Zhang, L., Luo, R., Yi, H., Liu, C., ... Rozelle, S. (2015). China’s left-behind children: Impact of parental migration on health, nutrition, and educational outcomes. Health Affairs, 34(11), 1964-1971. https://doi.org/10.1377/hlthaff.2015.0150

\section{Copyrights}

Copyright for this article is retained by the author(s), with first publication rights granted to the journal.

This is an open-access article distributed under the terms and conditions of the Creative Commons Attribution license (http://creativecommons.org/licenses/by/4.0/). 